\title{
The Effect of Neuromuscular Electrical Stimulation on Pulmonary Function, Gait Ability, and Quality of Life in Patients with Chronic Obstructive Pulmonary Disease
}

\author{
Jeong-il Kang ${ }^{1}$, Jun-Su Park², Dae-Keun Jeong ${ }^{1}$ \\ 'Department of Physical Therapy, Sehan University, Jeollanam-do; ${ }^{2}$ Haenam Hankook Hospital, Haenam, Korea
}

\begin{abstract}
Purpose: This study aims to investigate the changes in pulmonary function, gait ability, and quality of life when NMES is applied along with $\mathrm{CBE}$ and to provide basic clinical data to be used in pulmonary rehabilitation guidelines for patients with COPD to treat patients with severe COPD.

Methods: For this study, CBE and NMES of quadriceps femoris on both sides were applied to the experimental group $(n=10)$, and only CBE was applied to the control group $(n=10)$. For a pre-test, a 6-minute walk test was performed, and pulmonary function and healthrelated quality of life were measured. Moreover, an exercise program was applied to each group for 30 minutes per session, 5 times a week, for 6 weeks. After that, a post-test was conducted the same way as the pre-test.

Results: In the within-group comparison, there were significant differences in forced expiratory volume in one second, 6-minute walk test and health-related quality of life between the experimental group and the control group $(p<0.01)(p<0.05)$. In the between-group comparison, the experimental group showed an increase in forced expiratory volume in one second and 6 -minute walk test $(p<0.05)$ and showed a decline in health-related quality of life $(p<0.05)$.

Conclusion: The 6-weeks NMES program improved health-related quality in patients with severe COPD by increasing expiratory volume by reinforcing the function of quadriceps femoris. This finding implies that NMES could be an alternative mode for improving physical functions of patients with severe COPD, who cannot participate in a breathing exercise program or are reluctant to participate.
\end{abstract}

Keywords: Neuromuscular electrical stimulation (NMES), Complex breathing exercise (CBE), Chronic obstructive pulmonary disease (COPD)

\section{서 론}

만성폐쇄성폐질환(chronic obstructive pulmonary disease, $\mathrm{COPD}$ )은 적 절한 치료를 받아도 점차 진행되면서 의학적으로 완치가 어려운 질 환으로 전 세계적으로 유병률과 사망률이 증가하고 있다. Global initiative for chronic obstructive lung disease (GOLD)의 보고서에 따르면 2020년에는 만성폐쇄성폐질환이 전 세계 사망 원인의 3위가 될 것으 로 전망된다. ${ }^{\circ}$ 우리나라도 만성폐쇄성폐질환으로 인한 사망률이 점 차 증가하고 있으며, 특히 40 세 이상 성인 유병률은 $13.5 \%$ 로 주요한 건 강문제로 대두되고 있다. ${ }^{2}$

만성폐쇄성폐질환은 유해한 입자나 가스의 흡입에 의해 발생하는 폐의 비정상적인 염증반응과 점차 진행하는 기류제한을 보이는 호흡
곤란, 기침, 객담 등의 증상이 나타나는 호흡기질환으로, 종종 상당한 운동불내성(exercise intolerance)을 초래한다. 불충분한 산소 섭취, 골 격근 기능부전으로 인해 나타나는 운동불내성은 호흡 곤란과 함께 만성폐쇄성폐질환의 주요 장애요소 중 하나로 간주되며, 다리 통증 또한 흔히 보고되는 운동 제한 증상을 보인다. 이러한 사지근 기능 장 애의 임상 증상은 근육의 위축, 약화, 내구력 감소 및 근육 피로도가 포함된다. 따라서 만성폐쇄성폐질환 환자 관리에서 사지의 근육 기 능을 평가하는 것 또한 폐기능과 더불어 필요한 요소라 볼수 있다.

상지의 힘과 지구력은 하지보다 더 보전된 것으로 보고되고 있으 나, 특히 넙다리네갈래근(quadricepsfemoris)의 근력은 정상인에 비해 20-30\% 정도 저하되는 것으로 나타난다. ${ }^{5}$ 이러한 하지근력 저하의 정 도는 질환의 중증도인 1초간 노력성 날숨량(forced expiratory volume 
in one second, FEV1)과 비례하고, 6 분보행검사로 측정한 운동능력의 저하와도 직접적인 상관관계를 보인다. ${ }^{6}$ 넙다리네갈래근은 만성폐쇄 성폐질환의 사망률을 유의하게 예측할 수 있으며, 균형 장애 및 낙상 위험 증가와도 관련이 있다. 따라서 넙다리네갈래근의 기능을 향상 시키는 것이 만성폐쇄성폐질환 환자의 관리에서 중요한 치료 목표로 간주된다. 대부분의 만성폐쇄성폐질환 환자가 운동을 조기 종료하 는 이유는 호흡곤란뿐만 아니라 하지 근육의 피로 및 근력약화와 깊 은 관련이 있다. ${ }^{8}$ 이것은 골격근의 기능 이상이 이들 환자에서 운동 능력의 저하에 영향을 미친다는 것을 나타낸다. 따라서 만성폐쇄성 폐질환 환자의 운동능력을 높이고자 하는 노력은 끊임없이 대두되 고 있다. 이러한 맥락에서 하지에 신경근전기자극(neuromuscular electrical stimulation, NMES)의 적용은 운동이 힘든 만성폐쇄성폐질환 환 자에게 호흡곤란을 유발하지 않는 유용한 대체 훈련 전략으로 제안 되는 치료방법이다. ${ }^{9}$

신경근전기자극은 근력강화, 지구력강화, 근위축 및 약화 방지 등 의 목적에 사용되고 있으며, ${ }^{10}$ 정상 근육과 병리적 요인에 의해 저하된 근육의 기능을 향상시킨다고 하였다."1 또한 근육 소모를 줄이고 재활 기간 동안 근력의 회복을 최적화하는 데 도움을 주며, 척수 손상이 있 는 환자와 울혈성심부전으로 인한 골격근 기능 장애 및 운동불내성 을 가진 환자에서 호흡 기능을 보조하는 데 사용된다. 현재까지 보고 된 신경근전기자극의 연구에 따르면 Reeves 등'2은 신경근전기자극이 신경근 연접부위의 운동단위를 증가시킨다고 하였고, 신경근전기자극 으로 인해 넙다리네갈래근의 근력이 증가되었음을 보고하였으며, ${ }^{13-15}$ 이러한 전기자극은 세포내 투과도 및 탈분극 증가를 통해 전파되어 운동종판에 신경전달물질을 분비시키고 초기 적용 시엔 운동단위 동 원율 증가, 지속적 적용 시엔 근섬유의 산화능력을 증가를 일으켜 근 육의 유산소적 능력을 이끌어 낸다고 하였다. ${ }^{16}$ 자율적으로 자가-관리 될 수 있고, 신진 대사 부하가 적으며, 이동이 힘든 환자들에게 제공해 줄 수 있는 이점을 바탕으로, ${ }^{17}$ 이 중재방법은 만성폐쇄성폐질환 환자 의 폐기능, 운동능력 및 삶의 질 향상과도 관련이 있을 수 있다.

아직까지 국제적인 호흡재활지침에도 만성폐쇄성폐질환의 중증 도에 따른 운동방법이 세부적으로 분류되어 있지 않은 실정이다. 그 러므로 만성폐쇄성폐질환 환자가 운동 중에 호흡곤란의 정도를 최 대한 줄이고 환자 스스로 운동 수행 능력을 충분히 발휘할 수 있도록 하는 것이 필요하다. 따라서 본 연구는 넙다리네갈래근에 대한 신경 근전기자극의 적용이 만성폐쇄성폐질환 환자의 폐기능과 보행능력, 삶의 질에 미치는 영향을 분석함으로써 만성폐쇄성폐질환의 증상 개선 여부를 타진함과 동시에 이들의 호흡재활지침에 활용될 수 있 는 임상적 기초자료를 제공하기 위해 시행하였다.

\section{연구 방법}

\section{1. 연구대상}

본 연구는 2018년 2월부터 4월까지 전라남도에 소재한 $\mathrm{H}$ 병원에서 입 원중인 60-80세 연령범위의 남성 만성폐쇄성폐질환 환자 20 명을 대상 으로 하였다. $\mathrm{COPD}$ 의 진단은 GOLD 지침에 따라 등급을 분류하는 GOLD stage 범위가 중증인 대상자 중 내과적 질환(허혈성 심장질환, 간헐성파행증)을 병합하지 않은 자, 선천적인 가슴우리의 변형이나 늑골의 골절 등의 동반손상이 없는 자, 급진적 만성폐쇄성폐질환 증 상이 없는 자로 본 연구의 목적을 이해하고 연구에 참여하기로 동의 한 자를 대상자로 선정하였으며, 일반적 특성은 다음과 같다(Table 1).

본 연구는 세한대학교 생명 윤리위원회(IRB)의 승인을 받았다(승 인번호: SH-IRB 2018-03).

\section{2. 실험방법}

1) 연구 설계

만성폐쇄성폐질환 환자 20 명을 표본 추출하여 신경근전기자극을 병 행한 복합호흡운동을 중재한 실험군과 복합호흡운동을 중재한 대 조군을 각각 10 명씩 무작위 배치하여 6 주간, 5 일/주, 1 회/일, 30 분씩 중 재 프로그램을 시행하였다. 중재 전 폐활량 측정기를 활용하여 1 초당 노력성 날숨량(forced expiratory volume in 1 second, FEV1)과 노력성 폐활량(forced vital capacity, FVC)을 측정하였고, 6 분보행검사(6-minute walk test, 6MWT)로 6 분 동안의 이동거리를 측정하였다. 또한 세 인트호흡기설문지(St. George's respiratory questionnaire, SGRQ) 평가 를 사용하여 건강관련 삶의 질 평가를 측정한 후, 6 주 후에 사후검사 를 사전검사와 동일하게 재측정하여 분석하였다.

\section{2) 측정 도구 및 방법}

본 연구에 사용된 측정 도구로는 신장과 체중은 Body Mass Index HW-600 (Korea)을 사용하였고, 폐기능은 Chestgraph HI-701 (Chest, Japan)을 이용하여 1초당 노력성 날숨량, 노력성 폐활량을 측정하였 다. 그리고 운동능력은 6 분보행검사(6-minute walk test)로 이동거리를

Table 1. General chracteristics

$(n=20)$

\begin{tabular}{|c|c|c|c|}
\hline \multirow[t]{2}{*}{ Items } & $\begin{array}{l}\text { Experimental } \\
\text { group }(n=10)\end{array}$ & $\begin{array}{l}\text { Control group } \\
(n=10)\end{array}$ & \multirow[t]{2}{*}{$p$} \\
\hline & $M \pm S D$ & $\mathrm{M} \pm \mathrm{SD}$ & \\
\hline Age (year) & $69.30 \pm 5.21$ & $67.30 \pm 4.24$ & 0.45 \\
\hline Height (cm) & $169.40 \pm 3.38$ & $167.90 \pm 4.72$ & 0.12 \\
\hline Weight (kg) & $72.30 \pm 7.45$ & $71.70 \pm 5.25$ & 0.21 \\
\hline FEV1 (L) & $0.88 \pm 0.04$ & $0.89 \pm 0.06$ & 0.79 \\
\hline FVC (L) & $2.09 \pm 0.08$ & $2.13 \pm 0.11$ & 0.53 \\
\hline Test 6-MWT (m) & $248.60 \pm 52.98$ & $265.20 \pm 50.57$ & 0.11 \\
\hline
\end{tabular}


측정하였으며, 건강관련 삶의 질을 측정하기 위해 세인트호흡기설문 지(SGRQ)로 측정하였다.

\section{(1) 폐기능 측정}

폐기능 측정은 폐기능 측정기를 활용하여 대상자에게 앉은 자세에 서 호흡기계를 입에 물고 최대한 숨을 들이쉰 후, 힘껏 내뱉게 하여 측정된 수치를 기록하여 1 초당 노력성 날숨량과 노력성 폐활량을 측 정하였다. 폐활량 측정은 최소 3 회 이상 실시하였고, 검사치 중에서 가장 큰 수치와 그 다음 큰 수치 사이의 차이가 $5 \%$ 이내 또는 $200 \mathrm{~mL}$ 이내인 수치를 측정하였다.

\section{(2) 보행능력 측정}

일반적으로 만성폐쇄성폐질환 환자의 보행능력을 평가하기 위해 사 용되고 있는 6 분보행검사(6MWT)를 실시하였다. $6 \mathrm{MWT}$ 는 미국흥부 학회(American thoracic society)에서 제시한 6분보행검사에 대한 가이 드라인을 참고하여 $30 \mathrm{~m}$ 트랙을 6 분간 걷게 한 후 보행한 거리 $(\mathrm{m})$ 를 측정하였다. ${ }^{18}$

\section{(3) 건강관련 삶의 질 측정}

SGRQ는 만성폐쇄성폐질환 환자의 건강관련 삶의 질을 측정하기 위 해 고안된 자가보고 도구이며 총 50 문항의 3 가지 영역으로 이루어져 있는데, 지난 한 달 동안의 호흡기 증상의 빈도와 중증도를 반영하는 증상(symptom) 8문항, 호흡곤란을 유발하거나 호흡곤란에 의해 제 한받는 활동 정도를 반영하는 활동력(activity) 16 문항, 사회적 기능, 정서적 기능에 대한 질병의 영향, 전반적인 장애 정도를 측정하는 영 향력(impact) 26 문항으로 구성되어 있고, 영역별 점수와 총 점수를 각 각 계산하여 0 에서 100 까지 점수로 표시되는데 점수가 낮을수록 호 흡기 증상과 관련된 삶의 질은 좋으며 점수가 높을수록 삶의 질은 떨 어진다. 측정은 $1: 1$ 직접 면담으로 시행하였으며 피검자가 직접 문항 을 읽고 표기하기가 불가능할 경우 검사자가 피검자에게 각 문항을 읽어주고 자신의 상태를 가장 잘 나타내는 항목을 고르도록 하여 검 사자가 기록하였다.

\section{3. 중재방법}

\section{1) 복합호흡운동}

호흡운동은 총 6 주간, 주 5 회, 1 회 30 분 간 각 집단에 가로막 호흡운동 과 입술 오므리기 호흡을 복합하여 중재하였다. 호흡운동을 실시하 기 위해 환자를 바로 누워서 편안한 자세로 준비시키고 들숨성 가로 막 호흡운동이 끝나면 곧바로 날숨성 입술 오므리기 호흡운동을 시 행하였다. 총 4 session으로 구성되며 1 session이 끝난 후 1 분간의 휴식 시간을 제공하였으며, 1 session은 총 5 set로 이루어지며, 1 set당 분당
4-5회의 호흡운동을 시행하고 30 초의 휴식시간을 제공하였다. 들숨 성 가로막 호흡운동의 운동방법은 치료사의 손은 전방 갈비연골 바 로 아래 위치한 복직근에 올려놓은 다음 환자에게 느리고 깊게 코로 숨을 들이마시도록 들숨성 가로막 호흡을 유도한다. 이때 치료사는 배곧은근이 상승될 때 적절한 저항을 가하며 환자의 깊은 들숨을 유 도하며, 환자는 깊은 들숨을 하는 동안 어깨를 이완시켜 유지하게 하 고 위쪽 가슴부는 움직이지 않게 하며 복부의 상승만 허용한다. 날숨 성 입술 오므리기 호흡운동 운동방법은 환자는 깊은 들숨을 이용하 여 입술을 오므리고 일정한 시간동안 공기를 밖으로 내쉬도록 한다.

\section{2) 신경근전기자극}

실험군은 호흡운동이 끝난 후, 의자에 앉아있는 상태에서 2채널 Biostim NMS 2 (Biostim, USA)를 사용하여 양측 넙다리네갈래근의 운동점에 전극을 배치시켜 각각 30 분씩 중재하였다. 근육 수축력에 미치는 피로의 영향을 최소화하기 위해 신경근 전기자극은 대칭적 이상성 파형으로 하였고, $50 \mathrm{~Hz}$ 의 주파수(frequency), 맥동빈도(pulse rate) $50 \mathrm{pps}$, 맥동기간(pulse duration)은 $300 \mu \mathrm{s}$, 단속시간비(duty cycle) 는 전기자극 10 초, 단속시간은 30 초로 하였으며 1 회 30 분간 적용하였 다. 대상자가 참을 수 있고, 가시적인 근수축이 일어나는 최대 강도의 자극을 기록하여 중재기간 동일하게 자극하였다. ${ }^{19}$

\section{4. 자료분석}

본 연구의 자료처리 방법은 Window용 SPSS 17.0을 이용하여 연구대 상자의 일반적 특성 및 집단의 폐기능과 신체적기능을 Shapiro-wilk 로 정규성 검정하였고, 집단 내 변화 비교는 대응표본 t-검정(paired ttest)을, 집단 간 변화 비교는 공분산분석(ANCOVA)을 하였으며, 유의 수준 $\alpha=0.05$ 로 설정하였다.

\section{결 과}

\section{1. 집단 간 변화 비교}

1 초간 노력성 날숨량, 6 분보행검사에서는 실험군에서 높아지는 결과 를 나타내었고 $(\mathrm{p}<0.05)$, 건강관련 삶의 질에서는 실험군에서 낮아지 는 결과가 나타났다 $(\mathrm{p}<0.05)($ Table 2$)$.

\section{2. 실험군의 집단 내 변화 비교}

실험군에서 1 초간 노력성날숨량, 6 분보행검사, 건강관련 삶의 질에서 유의하게 높아지는 결과를 보였으며 $(\mathrm{p}<0.01)$, 노력성 폐활량에서는 유의한 차이가 없었다(Table 3). 
Table 2. Comparison of change between groups

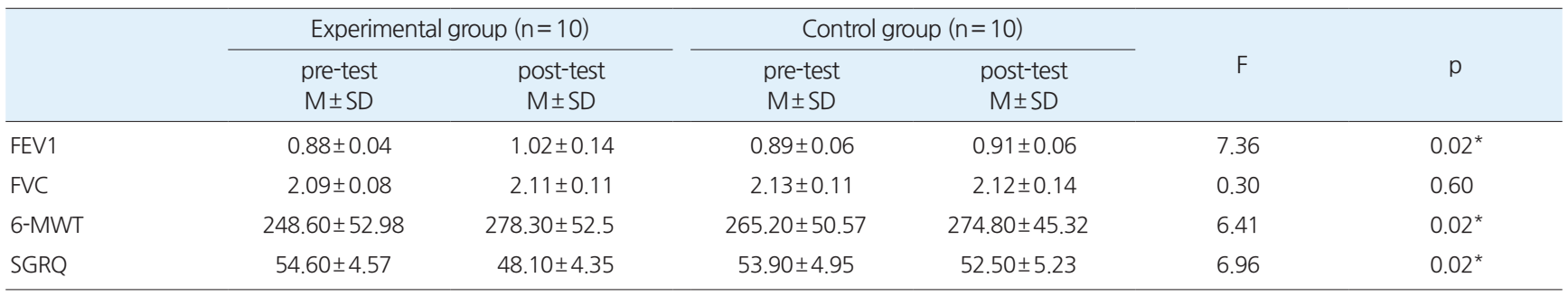

Values are presented as mean \pm standard deviation

FEV1: forced expiratory volume in 1 second, FVC: forced vital capacity, 6-MWT: six-minute walk test, SGRQ: St. George's respiratory questionnaire. ${ }^{*} \mathrm{p}<0.05$, significant differences between pre-post intervention.

Table 3. Comparison of change in experimental group

\begin{tabular}{|c|c|c|c|c|}
\hline & \multicolumn{2}{|c|}{ Experimental group $(n=10)$} & \multirow[b]{2}{*}{$\mathrm{t}$} & \multirow[b]{2}{*}{$\mathrm{p}$} \\
\hline & $\begin{array}{l}\text { Pre-test } \\
M \pm S D\end{array}$ & $\begin{array}{l}\text { Post-test } \\
M \pm S D\end{array}$ & & \\
\hline FEV1 & $0.88 \pm 0.04$ & $1.02 \pm 0.14$ & -3.43 & $0.01^{*}$ \\
\hline FVC & $2.09 \pm 0.08$ & $2.11 \pm 0.11$ & -0.67 & 0.52 \\
\hline 6-MWT & $248.6 \pm 52.98$ & $278.3 \pm 52.5$ & -4.80 & $0.00^{\star}$ \\
\hline SGRQ & $54.6 \pm 4.57$ & $48.1 \pm 4.35$ & 3.36 & $0.01^{*}$ \\
\hline
\end{tabular}

Values are presented as mean \pm standard deviation.

FEV1: forced expiratory volume in 1 second, FVC: forced vital capacity, 6-MWT: six-minute walk test, SGRQ: St. George's respiratory questionnaire.

${ }^{*} \mathrm{p}<0.05$, significant differences between pre-post intervention.

\section{3. 대조군의 집단 내 변화 비교}

대조군에서 1 초간 노력성날숨량, 6 분보행검사, 건강관련 삶의 질에서 유의하게 높아지는 결과를 보였으며 $(\mathrm{p}<0.05)$, 노력성 폐활량에서는 유의한 차이가 없었다(Table 4).

\section{고 찰}

본 연구에서는 중증의 만성폐쇄성폐질환 환자의 복합호흡운동과 넙 다리네갈래근에 신경근전기자극을 적용함으로써 폐기능과 운동능 력, 삶의 질에 미치는 영향을 알아봄으로써 보다 적합한 호흡운동 프 로그램의 효용성을 제시하고자 다음과 같은 논의를 하고자 한다.

만성폐쇄성폐질환이나 제한성 폐질환은 신경학적 손상에 의한 호 흡근육의 약화가 아니고 기도와 폐포의 기능 부전으로 환기기능의 감소가 원인이 되어 호흡관련 근육들에 기능 이상이 초래되는 질환 들이다. 특히 중증도 이상의 만성폐쇄성폐질환은 폐포벽의 탄력섬유 감소로 인한 날숨성 기류제한이 발생하고, 기도폐쇄 역시 마찬가지 로 폐의 과팽창에 중요한 요소로 인식되었다. ${ }^{20}$ 만성폐쇄성폐질환 환 자에서 훈련의 강도와 운동 시간은 중요한 결정 요소이며, 일반적으 로 호흡중재방법은 호흡곤란을 줄이고 신체기능 향상을 위해 6-12주 정도의 운동 및 교육프로그램을 중재하기를 권장하고 있다. ${ }^{21}$ 훈련 횟 수는 주 2-5회 시행하여야 하며 시간은 20-30분 운동을 실시하는 것 이 효과적이라고 하였는데, 이를 토대로 본 연구에서도 연구의 목적
Table 4. Comparison of change in control group

\begin{tabular}{|c|c|c|c|c|}
\hline & \multicolumn{2}{|c|}{ Control group $(n=10)$} & \multirow[b]{2}{*}{$\mathrm{t}$} & \multirow[b]{2}{*}{$\mathrm{p}$} \\
\hline & $\begin{array}{l}\text { pre-test } \\
\mathrm{M} \pm \mathrm{SD}\end{array}$ & $\begin{array}{l}\text { post-test } \\
\mathrm{M} \pm \mathrm{SD}\end{array}$ & & \\
\hline FEV1 & $0.89 \pm 0.06$ & $0.91 \pm 0.06$ & -2.42 & $0.04^{*}$ \\
\hline FVC & $2.13 \pm 0.11$ & $2.12 \pm 0.14$ & 0.45 & 0.64 \\
\hline 6-MWT & $265.2 \pm 50.57$ & $274.8 \pm 45.32$ & -2.41 & $0.04^{*}$ \\
\hline SGRQ & $53.9 \pm 4.95$ & $52.5 \pm 5.23$ & 3.28 & $0.01^{*}$ \\
\hline
\end{tabular}

Values are presented as mean \pm standard deviation.

FEV1: forced expiratory volume in 1 second, FVC: forced vital capacity, 6-MWT: six-minute walk test, SGRQ: St. George's respiratory questionnaire.

${ }^{*} p<0.05$, significant differences between pre-post intervention.

을 달성하기 위하여 치료시간을 6 주간, 주 5 회, 1 일 1 회, 1 회 30 분간 각 각 중재하였다.

$\mathrm{Kim}$ 등 22 은 뇌졸중 환자들을 대상으로 호흡근 강화운동이 가로 막의 강화로 인해 폐기능을 향상시킨다고 하였고, $\mathrm{Xu}$ 등 23 은 중증의 만성폐쇄성폐질환 환자를 대상으로 오므린 입술호흡운동과 가로막 호흡운동을 결합하여 3 개월 동안 중재한 결과, 폐기능과 삶의 질에 효과가 있었으며, Paulin 등 24 은 중증 만성폐쇄성폐질환 환자 54 명을 대상으로 가로막 호흡운동이 운동내성과 호흡곤란의 정도를 향상시 켜, 중증 만성폐쇄성폐질환 환자들에게 가로막의 운동성을 강조하였 다. 또한 Lee ${ }^{25}$ 은 정상성인 68 명을 대상으로 과부하 원리와 입술 오므 리기 호흡을 적용한 가로막 호흡운동이 호흡기능과 가로막 두께의 증가를 나타내 가로막 호흡운동이 가정 호흡재활 프로그램으로 유 용한 운동방법이라고 제시하였고, Yamaguti 등 26 은 가로막 호흡운동 이 만성폐쇄성폐질환 환자의 건강관련 삶의 질과 6 분 보행이 증가된 다고 하였다. 이러한 선행연구를 바탕으로 본 연구에서도 만성폐쇄 성폐질환 환자를 대상으로 6주간 가로막 호흡운동을 중재한 실험군 과 대조군에서 모두 1 초간 노력성 날숨량, 6 분보행검사, 삶의 질에서 각각 유의한 향상을 보였다. 이러한 결과는 흡기근 훈련을 통한 가로 막과 흡기보조근에 부하를 제공함으로써 환자의 날숨의 용량을 증 가시키고, 활동지수가 높아짐으로 인해 보행능력에도 유의한 향상 이 나타난 것으로 생각된다. 그러나 집단 내 노력성 폐활량에서는 실 험군과 대조군에서 모두 유의한 차이가 없었다. 그 이유는 심호흡 시 
움직임에 제한을 받는 중증 만성폐쇄성폐질환 환자는 가동범위의 제한으로 폐의 환기를 증가시키진 못하였기 때문에 폐활량의 증가는 나타나지 않은 것으로 사료된다. 이는 경추손상 환자에게 실시한 호 흡운동이 1 초간 노력성 날숨량에서는 유의한 효과가 나타났으나 노 력성 폐활량의 향상에는 도움을 주지 않는다는 $\operatorname{Sim}^{27}$ 의 연구와, 독립 적인 가로막 호흡운동군에서 노력성 폐활량이 유의한 차이가 없었 다는 $\operatorname{Lim}^{28}$ 의 연구와 비슷한 결과이다.

$J_{\text {Jung }}^{29}$ 은 가로막 호흡이 호흡동안의 에너지 활용을 감소시키기 위 해 폐기능뿐만 아니라 가로막의 근력과 복근강화를 위한 호흡운동 방법으로 중증도의 만성폐쇄성폐질환 환자에게 효과적이라고 하였 지만, 중증 만성폐쇄성폐질환 환자들에게 운동을 시키는 데는 한계 가 있다고 하였고, Kang 등 ${ }^{30}$ 은 중증 만성폐쇄성폐질환 환자는 호흡 기능의 저하로 조직에 공급하는 산소의 감소 및 젖산의 축적으로 인 해 신체적 피로가 유발되고, 호흡곤란으로 인하여 독립적인 생활이 어렵고 일상생활에 제한을 받게 되는 상황이 피로를 가중시키기 때 문에 호흡운동을 시행하더라도 다시 쉽게 피로가 형성되어 신체적 인 상태가 저하된다고 하였다.

Takita 드ㅇㅣㅣ은 신경근전기자극 중재 후 만성폐쇄성폐질환 환자에게 서 증가된 b-endorphin level이 증가가 호흡기관의 리듬생성 구성요소 에 기여하여, 호흡능력이 향상된다고 하였고, Quittan 등 ${ }^{2}$ 은 울혈성 심부전 환자에서 신경근전기자극 후 근력 및 운동 내성의 실질적인 증가를 보였으며, Karavidas 등 33 의 연구에서는 이러한 신경근전기자 극이 전신성 염증지표인 TNF-a를 감소시키고, b-endorphin level을 증 가시켜 신진대사와 환기 요구가 낮은 만성폐쇄성폐질환 환자들에게 운동 내성을 향상시킬 수 있다는 근거를 제시하였다.

Bustamante 등 ${ }^{34}$ 은 GOLD III-IV의 만성폐쇄성폐질환 환자 18 명을 대상으로 8 주 동안 넙다리네갈래근에 신경근전기자극을 주 3 일, 15 분 동안 실시한 결과, 6 분보행능력, 삶의 질 점수가 증가하였고, Vieira 등 35 은 20 명의 만성폐쇄성폐질환 환자들을 대상으로 양측 넙다리네 갈래근에 신경근전기자극을 8 주 동안 주 5 일, 1 일 2 회, 45 분씩 중재한 결과, 폐기능과 보행능력을 향상시켰다. 이러한 선행연구들은 신경근 전기자극만을 중재하여 실험군과 대조군 비교를 통해 효과를 입증 하였지만, 본 연구에서는 복합호흡운동을 병행한 신경근전기자극의 효과를 알아보았다. 그 결과 집단 간 비교에서 복합호흡운동과 신경 근전기자극을 적용한 실험군이 복합호흡운동만을 중재한 대조군에 비해 1 초간 노력성 날숨량, 6 분보행검사, 삶의 질에서 각각 유의한 향 상을 나타내어 선행연구들을 지지하였다. 이러한 결과는 넙다리네갈 래근의 신경근전기자극이 신진대사를 높이고, 운동내성을 향상시켜 폐기능까지 영향을 미친 것으로 생각되며, 운동내성이 증가되어 활 동지수가 넓어짐으로써 삶의 질에도 영향을 미친것으로 사료된다. 만 성폐쇄성폐질환에서 말초 근육기능과 전신운동 성능 간의 연관성을
연구한 Steiner 등 36 의 연구와, 운동수행의 향상 정도는 넙다리네갈래 근의 근력 증가와 걷는 동안 요구되는 환기감소와 관련이 있다는 $\mathrm{Vi-}$ vodtzev 등 ${ }^{37}$ 의 연구와도 비슷한 결과이다.

본 연구의 제한점으로는 연구대상자들이 1 개의 의료기관 내에서 치료를 받고 있는 60-80세 만성폐쇄성폐질환 환자들로 제한하였으 므로 모든 만성폐쇄성폐질환 환자에 대한 일반화에 있어서는 한계가 있다는 점과, 현재 투여하고 있는 약물에 대해서도 통제하는 데 어려 움이 있어 변수가 발생할 수 있다는 점, 그리고 일상생활을 통제하지 못하였기에 연구 결과에 영향을 미칠 수 있다는 점이다.

결론적으로 6 주간의 신경근전기자극 프로그램은 넙다리네갈래 근의 기능을 강화시킴으로써 중증 만성폐쇄성폐질환 환자들의 기능 적 운동 내성을 향상시키고, 날숨의 용량을 증가시켜 폐기능, 보행능 력, 삶의 질까지 향상시켰다. 신경근전기자극이 폐 재활을 대신하는 것으로 간주되어서는 안되지만, 이러한 결과는 부가적인 호흡운동 프로그램을 제공할 수 있고, 현재 폐재활 프로그램에 참여할 수 없거 나 꺼리는 중증 만성폐쇄성폐질환 환자들의 신체 기능의 측면을 개 선하기 위한 대체 수단이 될 수도 있을 것이라고 생각된다.

\section{감사의 글}

본 논문은 2018년 세한대학교의 학술연구비에 의하여 지원되었다.

\section{참고문헌}

1. Global Initiative for Chronic Obstructive Lung Disease (GOLD). Global strategy for the diagnosis, management and prevention of chronic obstructive pulmonary disease. GOLD. 2015.

2. Jeon CM, Oh KO. Prevalence of chronic obstructive pulmonary disease among adults over 40 years old in Korea, 2009-2013. Public Health Weekly Report, KCDC. 2015;8(15):334-6.

3. Man WD, Soliman MG, Gearing J et al. Symptoms and quadriceps fatigability after walking and cycling in chronic obstructive pulmonary disease. Am J Respir Crit Care Med. 2003;168(5):562-7.

4. Kang JI, Jeong DK, Choi H. The effect of fatigue of patients with chronic obstructive pulmonary disease on depression and the health-related quality of life. J Kor Phys Ther. 2014;26(4):262-8.

5. Choi JC, Han DU. The effects of quadriceps setting exercise and electrical stimulation on improvement of quadriceps muscle strength. J Kor Phys Ther. 2001;13(2):273-80.

6. Polkey MI, Spruit MA, Edwards LD et al. Six-minute-walk test in chronic obstructive pulmonary disease: minimal clinically important difference for death or hospitalization. Am J Respir Crit Care Med. 2013;187(4):382-6.

7. Seymour JM, Spruit MA, Hopkinson NS et al. The prevalence of quadriceps weakness in COPD and the relationship with disease severity. Eur Respir J. 2010;36(1):81-8.

8. Gagnon P, Saey D, Vivodtzev I et al. Impact of pre induced quadriceps 
fatigue on exercise response in chronic obstructive pulmonary disease and healthy subjects. J Appl Physiol. 2009;107(3):832-40.

9. Kim GW, Kim JS. Analysis of surface EMG power spectrum and muscle fatigue depending on the variable of neuromuscular electrical stimulation. J Kor Phys Ther. 2014;26(5):280-9.

10. Sbruzzi G, Schaan BD, Pimentel GL et al. Effects of low frequency functional electrical stimulation with 15 and $50 \mathrm{~Hz}$ on muscle strength in heart failure patients. Disabil Rehabil. 2011;33(6):486-93.

11. Jeong BO, Kwon YS, Kim JS. The effect of neuromuscular electrical stimulation on the spasticity of elbow flexor in stroke patients. J Kor Phys Ther. 1999;11(3):89-96.

12. Reeves ND, Narici MV, Maganaris CN. In vivo human muscle structure and function: adaptations to resistance training in old age. Exp physiol. 2004;89(6):675-89.

13. Park SJ, Lee JH, Lee DJ. The effects of electrical stimulation method on muscle strength, pain, range of motion, fear avoidance-belief in patients with anterior cruciate ligament reconstruction. J KAIS. 2017;18(6):53846.

14. Taradaj J, Halski T, Kucharzewski M et al. The effect of neuromuscular electrical stimulation on quadriceps strength and knee function in professional soccer players: return to sport after ACL reconstruction. Biomed Res Int. 2013;2013:802534.

15. Coghlan S, Crowe L, McCarthy Persson U et al. Electrical muscle stimulation for deep stabilizing muscles in abdominal wall. Conf Proc IEEE Eng Med Biol Soc. 2008;2756-9.

16. Park D, Ryu JS. Neuromuscular electrical stimulation for swallowing. J Kor Dysphagia Soc. 2016;6(1):1-6.

17. SillenMJ, Franssen FM, Vaes AW et al. Metabolic load during strength training or NMES in individuals with COPD: Results from the DICES trial. BMC Pulm Med. 2014;14:146.

18. Pohl PS, Duncan PW, Perera S et al. Influence of stroke-related impairments on performance in 6-minute walk test. J Rehabil Res Dev. 2002; 39(4):439-44.

19. Neder JA, Sword D, Ward SA et al. Home based neuromuscular electrical stimulation as a new rehabilitative strategy for severely disabled patients with chronic obstructive pulmonary disease (COPD). Thorax. 2002;57(4):333-7.

20. Black PN, Ching PS, Beaumont B et al. Changes in elastic fibres in the small airways and alveoli in COPD. Eur Respir J. 2008;31(5):998-1004.

21. Spruit MA, Singh SJ, Garvey C et al. An official American thoracic society/European respiratory society statement: Key concepts and advances in pulmonary rehabilitation. Am J Respir Crit Care Med. 2013;188(8): e13-64.

22. Kim BR, Kang JI, Kim YN et al. Effects of respiratory muscle strengthening exercise on respiratory function and activities of daily living in stroke patients. J Kor Phys Ther. 2017;29(1):1-6.

23. Wu X, Hou L, Bai W. Effects of breathing training on quality of life and activities of daily living in elderly patients with stable severe chronic obstructive pulmonary disease. Chin J Rehabili Med. 2006;21(4):307-10.
24. Paulin E, Yamaguti WP, Chammas MC et al. Influence of diaphragmatic mobility on exercise tolerance and dyspnea in patients with COPD. Respir Med. 2007;101(10):2113-8.

25. Lee HY. The effects of diaphragm breathing exercise and feedback breathing exercise on pulmonary function and diaphragm thickness in normal subjects. Daegu University. Dissertation of Doctorate Degree. 2015.

26. Yamaguti WP, Claudino RC, Neto AP et al. Diaphragmatic breathing training program improves abdominal motion during natural breathing in patients with chronic obstructive pulmonary disease: A randomized controlled trial. Arch Phys Med Rehabili. 2012;93(4):571-7.

27. Shim YJ. Improvement of respiratory function by breathing exercise in patients with cervical spinal cord injuries. International University of Korea. Dissertation of Master's Degree. 2012.

28. Lim SW. The effects of a thoracic mobilization exercise using the Kaltenborn-evjenth orthopedic manual therapy on the pulmonary function and respiratory muscle activity of adults in their 20's. Yongin University. Dissertation of Doctorate Degree. 2017.

29. Jeong DK. The effects of breathing exercise on respiratory synergist muscle activity and SpO2 in patients with chronic obstructive pulmonary disease. J Kor Phys Ther. 2015;27(4):234-9.

30. Kang JI, Jeong DK, Choi H. The effect of types of respiratory exercise on respiratory muscle activity and health-related quality of life of patients with severe chronic obstructive pulmonary disease. J Kor Phys Ther. 2016;28(1):46-51.

31. Takita K, Herlenius EA, Lindahl SG et al. Actions of opioids on respiratory activity via activation of brainstem mu-, delta- and kappa-receptors; an in vitro study. Brain Res. 1997;778(1):233-41.

32. Quittan M, Wiesinger GF, Sturm B et al. Improvement of thigh muscles by neuromuscular electrical stimulation in patients with refractory heart failure: A single-blind, randomized, controlled trial. Am J Phys Med Rehabil. 2001;80(3):206-14.

33. Karavidas AI, Raisakis KG, Parissis JT et al. Functional electrical stimulation improves endothelial function and reduces peripheral immune responses in patients with chronic heart failure. Eur J Cardiovasc Prev Rehabil. 2006;13(4):592-7.

34. Bustamante V, López de Santa María E, Gorostiza A et al. Muscle training with repetitive magnetic stimulation of the quadriceps in severe COPD patients. Respir Med. 2010;104(2):237-45.

35. Vieira PJ, Chiappa AM, Cipriano G Jr et al. Neuromuscular electrical stimulation improves clinical and physiological function in COPD patients. Respir Med. 2014;108(4):609-20.

36. Steiner MC, Singh SJ, Morgan MD. The contribution of peripheral muscle function to shuttle walking performance in patients with chronic obstructive pulmonary disease. J Cardiopulm Rehabil. 2005;25(1):43-9.

37. Vivodtzev I, Debigare R, Gagnon P et al. Functional and muscular effects of neuromuscular electrical stimulation in patients with severe COPD: A randomized clinical trial. Chest. 2012;141(3):716-25. 